\title{
Icariin: a Potential Compound for the Recovery of Tibial Dyschondroplasia Affected Chicken Via Up-Regulating BMP-2 Expression
}

\author{
Mujahid lqbal ', Hui Zhang ${ }^{1}$, Khalid Mehmood ${ }^{1,2}$, Aoyun Li', Xiong Jiang ${ }^{1}$, Yaping Wang ${ }^{1}$, Jialu Zhang ${ }^{1}$,
} Muhammad Kashif Iqbal ${ }^{1}$, Mujeeb Ur Rehman ${ }^{1}$, Wangyuan Yao ${ }^{1}$, Shijin Yang ${ }^{1 *}$ and Jiakui Li ${ }^{1,3^{*}}$

\begin{abstract}
Background: Tibial dyschondroplasia (TD) is a skeletal disease of fast growing chicken and other avian species. It is characterized by an avascular and non-mineralized growth plate, which leads to a deformed tibial bone and lameness. Unfortunately, this disease is not only responsible for causing huge economic losses but also raises animal welfare concerns. Icariin is a flavonoid, which is isolated from Epimedium pubescens herb, and it has been used to cure different diseases including bone fractures and osteoporosis.

Results: We designed this experiment to use icariin for the treatment of TD affect chickens; for this purpose, a total of 180 chicks were equally divided into three groups: control, TD and icariin. All the three groups were offered ad libitum same normal standard diet with an addition of thiram $(50 \mathrm{mg} / \mathrm{kg}$ ) from 3rd day to 7 th day in TD and icariin group in order to induce TD in chickens. After the induction of TD, the chickens in icariin groups were fed standard diet with an addition of icariin at the rate of $10 \mathrm{mg} / \mathrm{kg}$ in drinking water to check the therapeutic effect of this flavonoid on TD. Our results showed that the icariin helped in restoring the TD lesion into a normal structure with significantly $(P<0.05)$ up-regulating the bone morphogenetic protein-2 (BMP-2) expression in the tibial growth plates (GP).

Conclusions: Icariin increased the vascular area in the growth plate and decreased the average TD score. In conclusion, this study shows that icariin is a potential compound for the recovery of TD affected chickens via up-regulating the BMP-2 expression without posing a threat of ingestion of toxic veterinary drug residues to human beings upon the consumption of treated chickens.
\end{abstract}

Keywords: Chicken bone diseases, Tibial dyschondroplasia, Icariin, BMP-2, Gene expression

\section{Background}

Tibial dyschondroplasia (TD) is the among the most common leg pathology of meat-type poultry. A typical lesion of TD is a mass of non-vascularized growth plate (GP) cartilage (Fig. 1) at the proximal tibiotarsus and tarsometatarsus. Generally, it is believed that TD is a result of maturing chondrocytes which fail to go thorough terminal differentiation [1-5]. In mammals, osteochondrosis is a disease which resembles TD [5].

\footnotetext{
* Correspondence: 979329262@qq.com; lijk210@sina.com

${ }^{1}$ College of Veterinary Medicine, Huazhong Agricultural University, Wuhan 430070, People's Republic of China

Full list of author information is available at the end of the article
}

Bone morphogenetic proteins (BMPs) belong to the transforming growth factor- $\beta$ (TGF- $\beta$ ) superfamily and are responsible for the regulation of bone morphogenesis. These proteins have been associated to the differentiation and regeneration of bone [6, 7]. Recently, several studies have shown BMPs potentially regulate bone remodeling upon activating BMP signals in mice [8]. Moreover, BMP-2 is a known stimulator of bone-formation and osteoblastic differentiation [9]. Previously it has been reported, icariin up-regulate the BMP-2 expression in osteoblasts [10]. Hsieh et al. [9] found that, icariin contain the osteogenic properties via BMP-2/Smad pathway and nitric oxide (NO) synthesis. Nitric oxide regulates the Runx2

(c) The Author(s). 2018 Open Access This article is distributed under the terms of the Creative Commons Attribution 4.0 International License (http://creativecommons.org/licenses/by/4.0/), which permits unrestricted use, distribution, and reproduction in any medium, provided you give appropriate credit to the original author(s) and the source, provide a link to the Creative Commons license, and indicate if changes were made. The Creative Commons Public Domain Dedication waiver (http://creativecommons.org/publicdomain/zero/1.0/) applies to the data made available in this article, unless otherwise stated. 


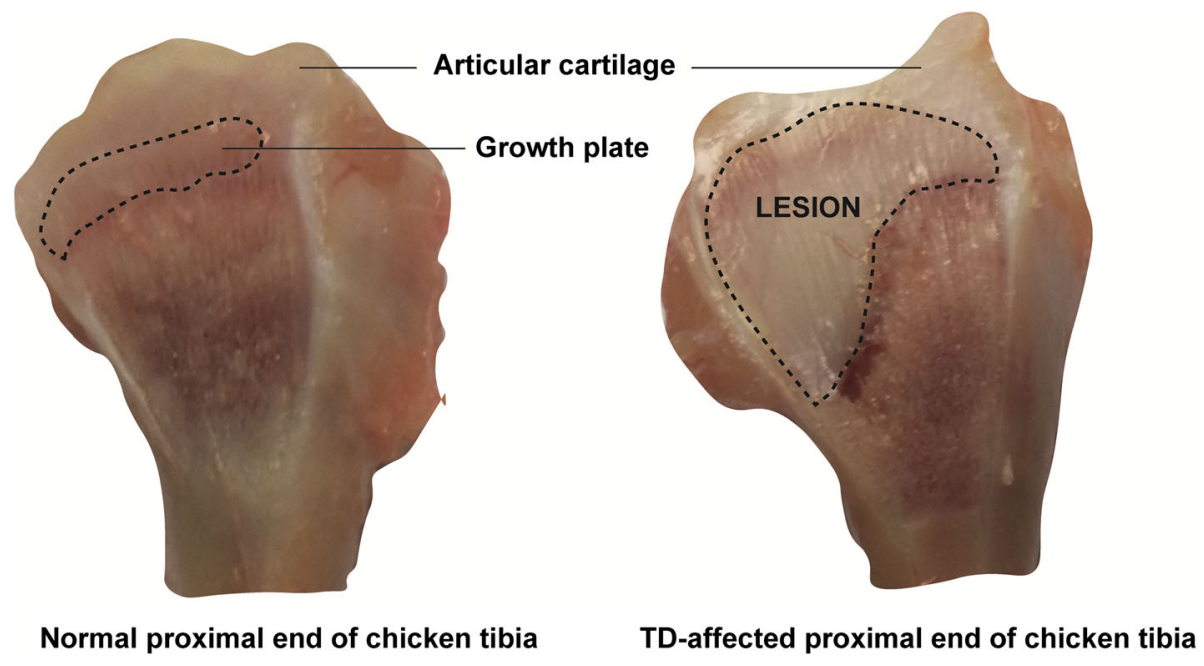

Fig. 1 A visual difference between the normal and TD affected tibial bone of chicken

gene expression, which further contribute to the proliferation and differentiation of osteoblasts and BMP-2/Smad pathway suppresses caspase-3; thus, restrict the apoptosis of osteoblasts. Liang et al. [7] stated that icariin enhances the bone formation via BMP-2/Smad4 transduction pathway in human osteoblastic cell line.

Icariin $\left(\mathrm{C}_{33} \mathrm{H}_{40} \mathrm{O}_{15}\right)$ is the main active compound of Epimedium pubescens, a Chinese herb recorded as "Yinyanghuo" in the Chinese pharmacopoeia. Chinese people have been using this medicine for decades to treat osteoporosis and bone fractures and to strengthen tendons [11, 12]. Previously, it has been reported that icariin can potentially repair bone and enhance bone formation. In addition to this, icariin has also been found to enhance bone regeneration [13, 14]. Several studies suggest the chondroprotective effects of icariin via promoting chondrogenesis and reducing the destruction of chondrocytes [15-17]. Therefore, in this study, we hypothesized that icariin is a potential compound to restore TD affected growth plate.

\section{Methods}

\section{Experimental Design}

A total of 180, one-day-old Arbor Acres chickens with an average weight of $47 \pm 0.5 \mathrm{~g}$ were obtained from a local hatchery (Chia Tai Animal Husbandry Co. Ltd., Wuhan). The chickens were divided equally into 3 groups (60 chickens each groups). Later, the groups were named as control, TD, and icariin and were offered ad libitum diet following the National Research Council (NRC, 1994) guidelines. All the groups were fed the same standard Vitamin D rich diet to prevent rickets. From day 4 to day 7 tetramethylthiuram disulphide (thiram) at the rate of $50 \mathrm{mg} / \mathrm{kg}$ of feed was offered in TD and icariin group to induce tibial dyschondroplasia
$[18,19]$. After day 7 , thiram was stopped in both groups and icariin was offered from day 8 to day 18 in the icariin group at the rate of $10 \mathrm{mg} / \mathrm{kg} /$ day to check the therapeutic effect this medicine on TD.

\section{Sample Collection and Handling}

The chickens were raised for 18 days and during this period lameness was recorded on a daily basis. Randomly ten chickens from each group were slaughtered by cervical dislocation on day $7,10,14$ and 18 . The severity of TD lesion was determined according to Simsa et al. [20] and Pines et al. [21]. In short, normal growth plate was denoted as 0 score, recognizable plug of cartilage in the longitudinal section of the proximal end of tibia was denoted as 1 score, $20 \%$ area covered by the lesion was denoted as 2 score, $50 \%$ area covered by the lesion was denoted as 3 score and $80 \%$ area covered by the lesion was indicated as 4 score. An average score for each group was obtained by dividing the total score of all tibial bones in that group with total number of tibial bones. Immediately after TD scoring, tibial bones were stored in $4 \%$ paraformaldehyde for hematoxylin and eosin $(H \& E)$ staining and few of them were stored in liquid nitrogen at $-70{ }^{\circ} \mathrm{C}$ for Western blotting and reverse transcription quantitative real-time polymerase chain reaction (RT-qPCR) analysis.

\section{Hematoxylin and Eosin (H\&E) Staining and Immunohistochemistry (IHC)}

$H \& E$ staining of the proximal end of tibia bone was performed in order to observe normal structures in control group, damaged structures in TD group and to observe the extent of recovery in icariin group. Vascular area in growth plate was measured using Image-Pro Plus software by assigning different color codes to blood vessels 
and the rest of GP. The tibiotarsal bone samples stored in paraformaldehyde were exposed to $10 \%$ ethylenediamine tetra acetic acid for decalcification. After that, cleaning of bone samples was done by xylene and were embedded in paraffin wax. Subsequently, a 4-5 $\mu \mathrm{m}$ thickness sections were cut to prepare histological slides. H\&E staining was performed according to a previously described method with slight modifications [22] and IHC was done according to an earlier reported method [23]. Several previous studies has demonstrated that BMP-2 are expressed in chondrocytes of GP, and may play an important role in their differentiation [24]. Therefore, we evaluated the BMP-2 antibody expression in GP via immunohistochemistry. The slides were washed in phosphate-buffered saline (PBS) and peroxidase-blocking solution (Boster, Wuhan). After that, the slides were incubated with 1:2000 dilutions of primary antibody against BMP-2 (ABclonal technology, Wuhan) at $4{ }^{\circ} \mathrm{C}$ overnight. Later the slides were washed using PBS and were incubated at $37{ }^{\circ} \mathrm{C}$ for $1.5 \mathrm{~h}$ with horseradish peroxidase-conjugated anti-rabbit secondary antibodies (Tuojie biological technology Co. Ltd., Wuhan). These immunolabeled slides were then examined under the microscope (Olympus CX31, Japan) and at last, primary antibodies were removed from negative control.

\section{RNA Extraction and RT-qPCR}

GP tissue from each group was separated and homogenized using TRIzol reagent (Invitrogen, Carlsbad, CA, USA) for the extraction of total RNA, which was transcribed into cDNA using a First-Strand cDNA synthesis kit (Tian Gen, China). Primers for BMP-2 were designed by using Primer Premier Software and were synthesized by Wuhan Qingke biotech. Co. Ltd. (Wuhan) based on the sequences published in GenBank database. The reaction mixture was normalized against the reference gene GAPDH. All the RT-qPCR reactions were performed in quadruplex using Step One-Plus ${ }^{\mathrm{Ta}}$ RT-qPCR system (Applied Biosystems). RT-qPCR reaction system was composed of $10 \mu \mathrm{L}$ SYBR reaction mix (Transgen Biotech) forward and reverse primers of a working concentration of $10 \mu \mathrm{L} \mathrm{mol} / \mathrm{L}, 2 \mu \mathrm{L}$ of cDNA and nuclease free water for a total volume of $20 \mu \mathrm{L}$. All the reactions were performed with the following thermal cycling parameters: $95{ }^{\circ} \mathrm{C}$ for $30 \mathrm{~s}$ (sec), 40 amplification cycles at $95{ }^{\circ} \mathrm{C}$ for $8 \mathrm{~s}, 59{ }^{\circ} \mathrm{C}$ for a time of $30 \mathrm{~s}$ and $70{ }^{\circ} \mathrm{C}$ for $30 \mathrm{~s}$. Relative quantification was performed using delta $(\Delta \mathrm{Ct})$ method [25].

\section{Western Blot Analysis}

GP was homogenized in ice-cold PBS, stored at $4{ }^{\circ} \mathrm{C}$ for $2 \mathrm{~h}$. Later, the supernatant was collected after the centrifugation at $14,000 \mathrm{x}$ g for $10 \mathrm{~min}$. Total protein concentration was determined by BCA protein detection kit (Service
Biotechnology, Wuhan, China) and the samples were stored at $-70{ }^{\circ} \mathrm{C}$. Protein was separated by sodium dodecyl sulfate polyacrylamide gel electrophoresis (SDS-PAGE) until the dye band reached the end of gel (10\% polyacrylamide gel) and was transferred on polyvinylidene difluoride (PVDF) membrane. These membranes were incubated in $5 \%$ skimmed milk for $1.5 \mathrm{~h}$ at room temperature. Subsequently, the membranes were incubated at $4{ }^{\circ} \mathrm{C}$ for overnight with rabbit monoclonal anti-BMP-2 primary antibodies (1:1000 dilution). Membranes were washed with tris-buffred saline tween (TBST) with a time span of $5 \mathrm{~min}$ for each time. Membranes were incubated at room temperature for $30 \mathrm{~min}$ with secondary antibody (1:3000 dilution) and were washed again with TBST 4 times. Finally, after washing the images were taken using an imaging system (UVP, Upland, CA, USA).

\section{Statistics}

Data was examined by a one-way analysis of variance (ANOVA) and student t-test using SPSS software (version 19.0) and presented as means \pm standard error of means (S.E.M). The difference between control and treatment groups was considered significant if $P<0.05$.

\section{Results}

\section{Morphological Observations}

As the thiram was started on the day 4 to induce TD, the chickens started showing typical signs of TD and associated lameness. The possibility of rickets was ruled out by feeding vitamin $\mathrm{D}$ rich diet. It was observed that lameness because of TD increased from day 4 to day 10 with a notable decline afterwards in TD group as the thiram was removed. Lameness in icariin group (treatment group) was less as compared to the TD group and based on morphological and histological observation it was observed that TD was restored largely (Fig. 2).

An average TD score on day 18 has been presented in Fig. 2. Average TD score in icariin group was non-significantly different on day 10 and 14, however, a gradual decrease in TD score was observed on day 10 and 14 . Therefore, chickens started regaining the ability to stand and walk properly after the icariin administration. The physical appearance and the walking ability of chickens were almost similar as compared to the control group on day 18 after the continuous administration of icariin. There were no signs of lameness in control group throughout the experiment.

\section{Effect of Icariin on the GP of Thiram Induced TD}

Histopathological observations showed, a mass of un-vascularized nature was present at the proximal end of tibia with a prominent cell death or apoptosis, irregular chondrocytes and degradation in thiram fed chickens 

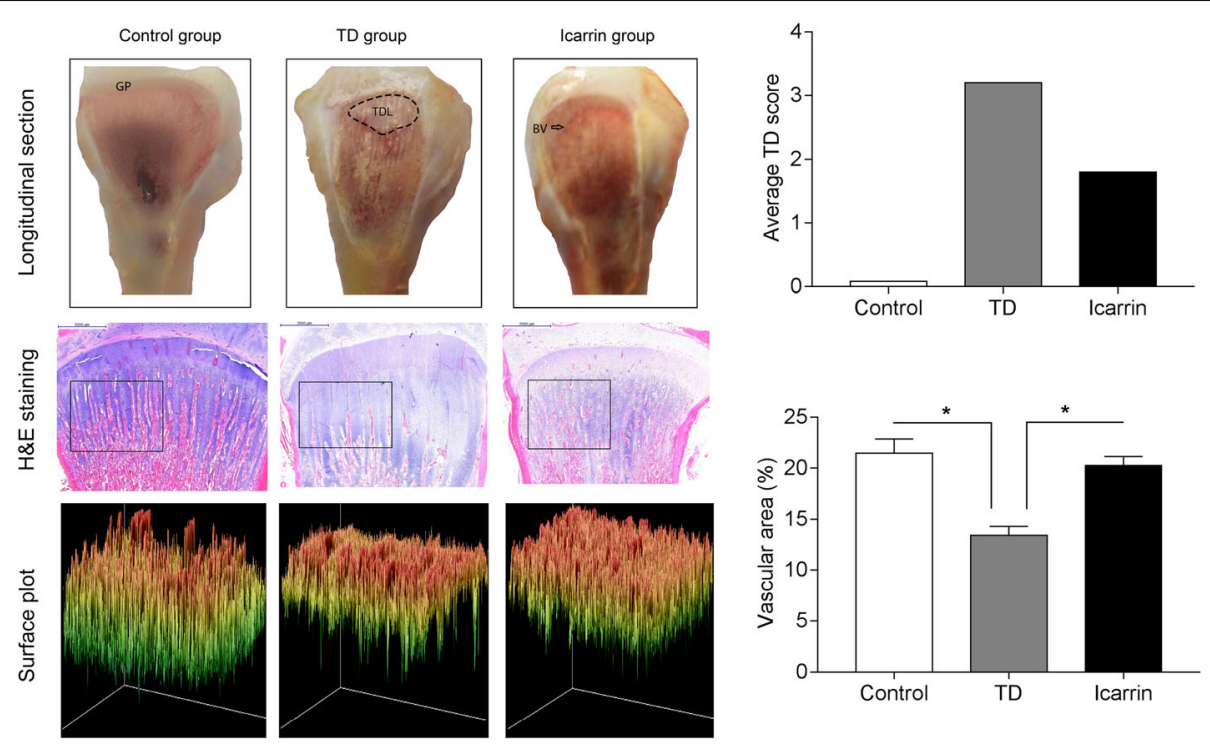

Fig. 2 The morphological changes of growth plates in the proximal end of tibia (Longitudinal section and H \& E staining) on day 18. Average TD score graph on day 18 (Upper graph). Surface plot of trabecular bone was generated and analyzed by Image-Pro Plus. Vascular area on day 18 (Lower graph) showing the percentage of blood vessel in different groups. ${ }^{*} P<0.05$

(TD group) on day $7,10,14$ and 18 . While the control group showed a normal GP with regular chondrocytes and columns. Large number of blood vessel were also observed in proliferation and hypertrophic zone in control group. However, icariin group showed a gradual improvement after the administration of icariin on day 10 , 14 and 18. Icariin treatment restored the blood vessel formation and chondrocytes differentiation in GP (Fig. 2).

\section{Immunohistochemical Localization of BMP-2 and Protein Expression in GP}

Immunohistochemical results showed that a less number of cells localized BMP-2 in TD suffering chickens as compared to the control and icariin treated group (Fig. 3). On day 18, BMP-2 expression was significantly decreased $(P<0.01)$ in TD group as compared to the control group. While, icariin administration significantly $(P<0.01)$ up regulated the expression of BMP-2 in the GP of treated chickens (Fig. 4a) as compared to the TD group. Protein level was determined by Western blot analysis on the day 7, 10,14 and 18 in tibia bone of each group. The level of BMP-2 protein was significantly $(P<0.01)$ down regulated on day 7 and onward in TD group while it was significantly $(P<0.01)$ increased after the treatment with Icariin on day 18 (Fig. 4b).

\section{Discussion}

Poultry is major source of protein and the demand of poultry meat and other by-products are increasing day-by-day throughout the world [26]. Among other poultry diseases, skeletal problems are a major cause of economic losses [27]. Tibial dyschondroplasia is a metabolic disease of cartilage in the growth plate of chicken and other poultry species. TD is causing economic losses to the poultry industry by low yield and poor quality of meat [3]. It is believed that TD is caused by several reasons in fast growing chickens. However, recent research has found that bone reformation and remodeling play a key role in TD pathogenesis. TD lesion is characterized by an uneven white, non-mineralized and avascular mass of cartilage in the GP. While a normal avian GP shows regularly arranged long chondrocytes with plenty of blood vessels $[1-3,22,28]$. Chickens suffering from TD usually show difficulty in standing and walking, which ultimately leads to less feed intake and sometimes even death [22, 28, 29]. Our results in this study were also in accordance to the previously observed clinical symptoms. However, the icariin administration to the thiram-induced TD chickens significantly reduced the lameness by reducing the TD lesion and by improving the vascularization of chicken growth plate.

Chinese herbs are considered economical and safe because of their less toxicity [30]. Icariin is a flavonoid, which is isolated from Epimedium pubescens herb, and it has been used to cure different diseases including bone fractures and osteoporosis [31]. It promotes the bone formation and significantly increases the mineral contents and bone mineral density $[7,10]$. The reason behind the wide use of icariin as a potential alternative therapy for bone diseases is the capability of icariin to promote osteoblast proliferation and osteogenic differentiation [12, 32]. However, to the best of our knowledge no previous studies used this medicine to treat TD in chickens in relation to BMP-2. 

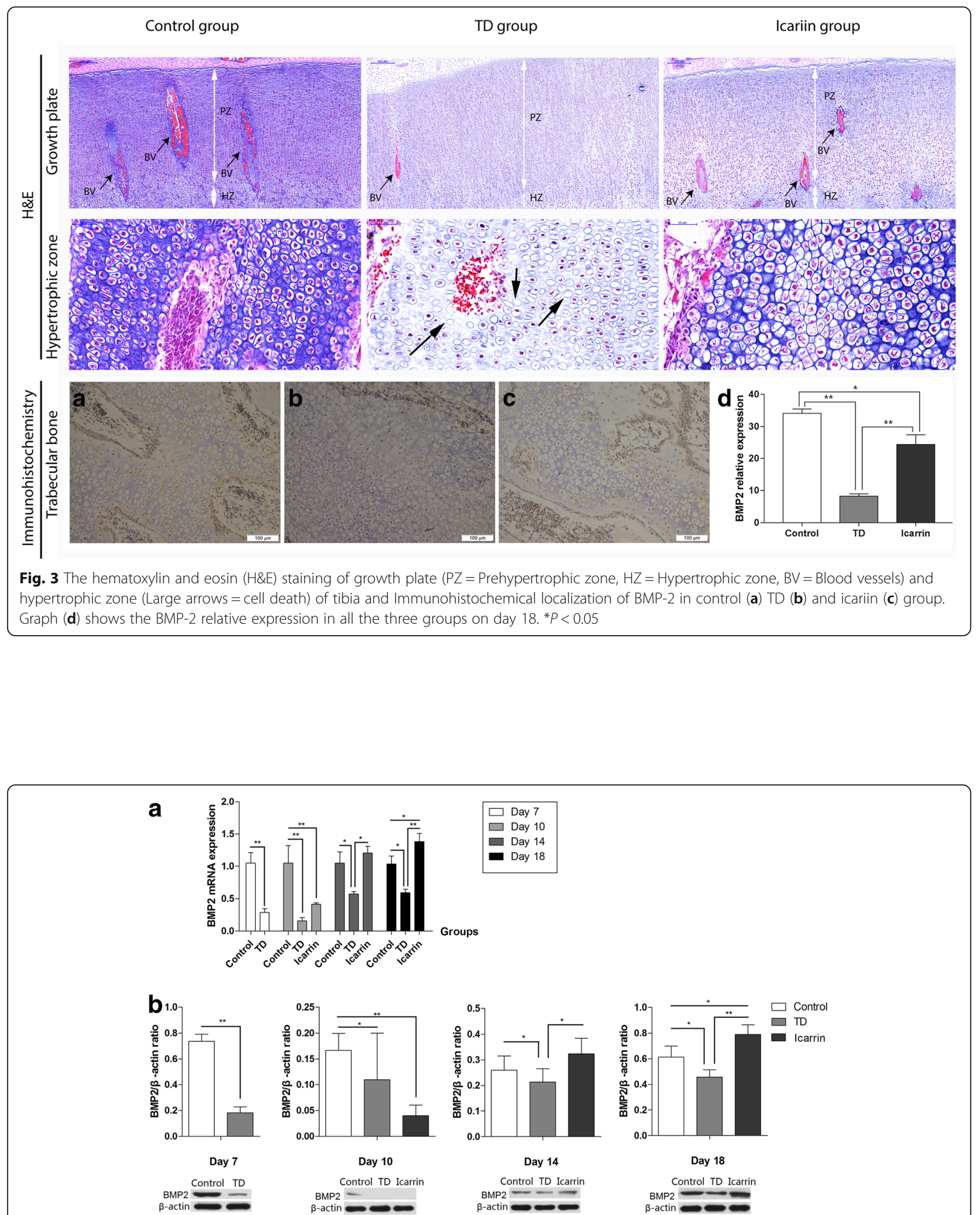

Fig. 4 Real-time quantitative PCR analysis and protein levels of BMP-2 were analyzed in growth plate on day 7, 10, 14 and 18. a The mRNA levels of BMP-2 was detected by RT-qPCR; $\mathbf{b}$ The protein levels of BMP-2 was detected by Western blotting. Western blot bands were quantified by Image $J^{\circledast} .{ }^{*} P<0.05,{ }^{* *} P<0.01$ 
In this experiment, thiram (fungicide) was used for the induction of TD. Thiram has been known for causing TD in chicken and other poultry species [1, 2] Excess growth was present in tightly arranged immature cartilage cells in TD group on day 7,10,14 and 18; there were scarce blood vessels in proliferation zone. Apoptosis and cell death was observed in the histopahological slides of severe TD lesions (Fig. 3). However, after treating the TD affected group with icariin the chickens regained the normal tibial structure and physically showed an ability to stand and walk properly.

BMPs play an essential role in the maintenance and repair of bone [33]. Recent studies show that icariin has been used to treat and understand the recovery mechanisms in bone related issues via regulating BMP-2. Icariin promote the bone formation via BMP-2/Smad pathway and nitric oxide synthesis [9]. As, BMP-2, along with other BMPs belong to TGF- $\beta$ superfamily that stimulate the bone and cartilage formation. In this regard, Yin et al. [10] reported that icariin can significantly increase the proliferation and differentiation of osteoblasts in human via up-regulating the BMP-2 expression. Similar findings were published in another recent study, Zhang et al. [34] found that flavonoids of Herba Epimedii (icariin) can promote the osteogenic differentiation through the increased mRNA expression of BMP-2 in human bone marrow-derived mesenchymal stem cells. In another in vitro study, icariin was also shown to stimulate the MC3T3-E1 differentiation by inducing BMP-2 expression [8]. In this experiment, icariin significantly up-regulated the BMP-2 expression on day 14 and 18 in diseased chicken. Our results regarding the effect of icariin on BMP-2 expression were similar to above the mentioned studies and various other studies [7, 35].

\section{Conclusions}

We conclude that icariin is a potential compound in promoting the angiogenesis in TD affected growth plates and it can significantly increase the BMP-2 expression. Considering the economic losses caused by TD and the cost of Icariin. We believe, icariin is a valuable alternative therapeutic agent for TD and deserves further research attention.

\footnotetext{
Abbreviations

BMP-2: Bone morphogenetic protein-2; GP: Growth plates; H\&E: Hematoxylin and eosin; IHC: Immunohistochemistry; NO: Nitric oxide; PBS: Phosphatebuffered saline; PVDF: Polyvinylidene difluoride; RT-qPCR: Reverse transcription quantitative real-time polymerase chain reaction; SDS-PAGE: Sodium dodecyl sulfate polyacrylamide gel electrophoresis; TBST: Tris-buffred saline tween; TCMs: Traditional Chinese medicines; TD: Tibial dyschondroplasia; TGF$\beta$ : Transforming growth factor- $\beta$
}

\section{Funding}

The study was supported by the National Key R\&D Program of China (Project No. 2017YFD0502200) and supported by the Fundamental Research Funds for the Central Universities (No. 2662017QD015).

\section{Authors' Contributions}

Experiment design: MI, HZ, KM \& JL. Performed the experiments: MI, HZ, XJ, KM \& WY. Contribution of reagents and materials: Al, YW, JZ \& MR. Data analysis: MI, HZ, MK, SY \& JL. Manuscript write up: MI, HZ, SY \& JL. All authors read and approved the final manuscript.

\section{Ethics Approval and Consent to Participate}

All the experiments related to animal trials were approved and maintained to meet the ethics guidelines of Ethics Committee of Huazhong Agricultural University (HZAU), Wuhan, P.R.China. Besides this all-possible care of chickens was taken to ensure their maximum welfare.

\section{Competing Interests}

The authors declare that they have no competing interests.

\section{Publisher's Note}

Springer Nature remains neutral with regard to jurisdictional claims in published maps and institutional affiliations.

\section{Author details}

${ }^{1}$ College of Veterinary Medicine, Huazhong Agricultural University, Wuhan 430070, People's Republic of China. ${ }^{2}$ University College of Veterinary and Animal Sciences, The Islamia University of Bahawalpur, Punjab, Pakistan. ${ }^{3}$ College of Animal Husbandry and Veterinary Medicine, Tibet Agricultural and Animal Husbandry University, Linzhi, Tibet 860000, People's Republic of China.

Received: 15 January 2018 Accepted: 24 May 2018

Published online: 01 July 2018

\section{References}

1. Iqbal MK, Liu J, Nabi F, Rehman MU, Zhang H, Tahir AH, et al. Recovery of Chicken Growth Plate by Heat-Shock Protein 90 Inhibitors Epigallocatechin3-Gallate and Apigenin in Thiram-Induced Tibial Dyschondroplasia. Avian Dis [Internet]. 2016;60:773-8. Available from: http://www.bioone.org/doi/10. 1637/11425-041816-Reg

2. Rath NC, Richards MP, Huff WE, Huff GR, Balog JM. Changes in the tibial growth plates of chickens with thiram-induced dyschondroplasia. J Comp Pathol. 2005;133:41-52.

3. Nabi F, Shahzad M, Liu J, Li K, Han Z, Zhang D, et al. Hsp90 inhibitor celastrol reinstates growth plate angiogenesis in thiram-induced tibial dyschondroplasia. Avian Pathol. 2016:45:187-93.

4. Tian WX, Zhang WP, Li JK, Bi DR, Guo DZ, Pan SY, et al. Identification of differentially expressed genes in the growth plate of broiler chickens with thiram-induced tibial dyschondroplasia. Avian Pathol. 2009;38:161-6.

5. Praul CA, Ford BC, Gay CV, Pines M, Leach RM. Gene expression and tibial dyschondroplasia. Poult Sci. 2000;79:1009-13.

6. Reddi AH. Initiation and promotion of Endochondral bone formation by bone morphogenetic Proteins : potential implications for avian Tibial Dyschondroplasia. Poult. Sci. Oxford University Press Oxford, UK. 2000;79:978-81.

7. Liang W, Lin M, Li X, Li C, Gao B, Gan H, et al. Icariin promotes bone formation via the BMP-2 / Smad4 signal transduction pathway in the hFOB 1. 19 human osteoblastic cell line. Int J Mol Med Spandidos Publications. 2012;2:889-95

8. Cao H, Ke Y, Zhang Y, Zhang CJ, Qian W, Zhang GL. Icariin stimulates MC3T3-E1 cell proliferation and differentiation through up-regulation of bone morphogenetic protein-2. Int J Mol Med. 2012;29:435-9.

9. Hsieh TP, Sheu SY, Sun JS, Chen MH, Liu MH. Icariin isolated from Epimedium pubescens regulates osteoblasts anabolism through BMP-2, SMAD4, and Cbfa1 expression. Phytomedicine Elsevier. 2010;17:414-23.

10. Yin X, Chen Z, Liu Z, Ma Q-J, Dang G. Icariine stimulates proliferation and differentiation of human osteoblasts by increasing production of bone morphogenetic protein 2. Chin Med J [Internet]. Chinese Medical Association. 2007;120:204-10. Available from: http://www.ncbi.nlm.nih.gov/ pubmed/17355822.

11. Wu H, Lien EJ, Lien LL. Chemical and pharmacological investigations of Epimedium species: a survey. Prog. Drug res. [internet]. Springer. 2003;60:1-57. Available from: https:/www.ncbi.nlm.nih.gov/pubmed/12790338

12. Chen KM, Ge BF, Ma HP, Liu XY, Bai MH, Wang Y. Icariin, a flavonoid from the herb Epimedium enhances the osteogenic differentiation of rat primary bone marrow stromal cells. Pharmazie [internet]. Govi-Verlag. 2005;60:939-42. 
Available from: http://www.ncbi.nlm.nih.gov/entrez/query.fcgi?cmd= Retrieve\&db=PubMed\&dopt=Citation\&list_uids $=16398272$

13. Li D, Yuan T, Zhang $X$, Xiao Y, Wang R, Fan Y. Icariin: a potential promoting compound for cartilage tissue engineering. Osteoarthr Cartil Elsevier. 2012; 20:1647-56.

14. Mo Z, Li W, Zhai Y, Gong Q. Icariin attenuates OGD/R-induced autophagy via $\mathrm{BCl}-2$-dependent cross talk between apoptosis and autophagy in PC12 cells. Evidence-Based Complement Altern Med Hindawi. 2016;2016

15. Zhang L, Zhang X, Li KF, Li DX, Xiao YM, Fan YJ, et al. Icariin promotes extracellular matrix synthesis and gene expression of chondrocytes in vitro. Phyther Res Wiley Online Library. 2012;26:1385-92.

16. Chao Wei C, Qi Ping D, Tian You F, Yong Qiang C, Tao C. Icariin prevents cartilage and bone degradation in experimental models of arthritis. Mediators Inflamm Hindawi. 2016;2016

17. Liu N, Zhang T, Cao B-R, Luan F-Y, Liu R-X, Yin H-R, et al. Icariin possesses chondroprotective efficacy in a rat model of dexamethasone-induced cartilage injury through the activation of miR-206 targeting of cathepsin K. Int J Mol Med Spandidos Publications. 2018;41:1039-47.

18. Rath NC, Huff WE, Balog JM, Huff GR. Comparative efficacy of different dithiocarbamates to induce tibial dyschondroplasia in poultry. Poult Sci Oxford University Press Oxford, UK. 2004;83:266-74.

19. Mehmood K, Zhang H, Li K, Wang L, Rehman MU, Nabi F, et al. Effect of tetramethylpyrazine on tibial dyschondroplasia incidence, tibial angiogenesis, performance and characteristics via HIF-1 a/NEGF signaling pathway in chickens. Sci Rep [Internet]. Springer US; 2018;8:2495. Available from: http://www.nature.com/articles/s41598-018-20562-3

20. Simsa S, Hasdai A, Dan H, Ornan EM. Induction of Tibial Dyschondroplasia in turkeys by Tetramethylthiuram Disulfide (Thiram). Poult. Sci. [Internet]. Oxford University Press Oxford, UK; 2007;86:1766-71. Available from: http://ps.oxfordjournals.org/content/86/8/1766.full

21. Pines M, Hasdai A, Monsonego-Ornan E. Tibial dyschondroplasia - tools, new insights and future prospects. Worlds Poult Sci J [nternet]. 2005;61:285-97. Available from: http://www.journals.cambridge.org/abstract_S0043933905000231

22. Tian W, Li J, Qin P, Wang R, Ning G, Qiao J, et al. Screening of differentially expressed genes in the growth plate of broiler chickens with tibial dyschondroplasia by microarray analysis. BMC Genomics [Internet]. 2013;14: 276. Available from: http://www.pubmedcentral.nih.gov/articlerender. fcgi?artid $=3648502 \&$ tool $=$ pmcentrez\&rendertype $=$ abstract.

23. Herzog A, Genin O, Hasdai A, Shinder D, Pines M. Hsp90 and angiogenesis in bone disorders-lessons from the avian growth plate. Am J Physiol Regul Integr Comp Physiol [Internet]. 2011;301:R140-7. Available from: http:// www.ncbi.nlm.nih.gov/pubmed/21562096

24. Anderson HC, Hodges PT, Aguilera XM, Missana L, Moylan PE. Bone Morphogenetic Protein (BMP) Localization in Developing Human and Rat Growth Plate, Metaphysis, Epiphysis, and Articular Cartilage. J. Histochem. Cytochem. [Internet]. Journal of Histochemistry \& Cytochemistry; 2000;48: 1493-1502. Available from: http://journals.sagepub.com/doi/10.1177/ 002215540004801106

25. Livak KJ, Schmittgen TD. Analysis of relative gene expression data using real-time quantitative PCR and the $2-\Delta \Delta C T$ method. Methods. Elsevier; 2001;25:402-408

26. Scanes CG. The global importance of poultry. Poult Sci Oxford University Press Oxford, UK. 2007:86:1057-8.

27. Cook ME. Skeletal deformities and their causes: introduction. Poult Sci [Internet]. 2000;79:982-4. Available from: http://www.ncbi.nIm.nih.gov/ pubmed/10901198

28. Nabi F, Li K, Shahzad M, Han Z, Zhang D, Liu J, et al. Gambogic acid inhibits Hsp90 expressions in thiram-induced tibial dyschondroplasia. Pak Vet J. 2016;36:224-6.

29. Mehmood K, Zhang H, lqbal MK, Rehman MU, Shahzad M, Li K, et al. In Vitro Effect of Apigenin and Danshen in Tibial Dyschondroplasia Through Inhibition of HeatShock Protein 90 and Vascular Endothelial Growth Factor Expressions in Avian Growth Plate Cells. Avian Dis. [Internet]. American Association of Avian Pathologists; 2017;61:372-7. Available from: https//doi.org/10.1637/11641-032817-RegR

30. Tan HL, Chan KG, Pusparajah P, Saokaew S, Duangjai A, Lee LH, et al. Anticancer properties of the naturally occurring aphrodisiacs: Icariin and its derivatives. Front Pharmacol. 2016;7:1-18.

31. Yang JX, Fichtner I, Becker M, Lemm M, Wang XM. Anti-proliferative efficacy of icariin on HepG2 hepatoma and its possible mechanism of action. Am J Chin Med [Internet]. 2009;37:1153-65. Available from: http://www.ncbi.nIm. nih.gov/pubmed/19938223
32. Zhao J, Ohba S, Komiyama Y, Shinkai M, Chung U, Nagamune T. Icariin: a potential osteoinductive compound for bone tissue engineering. Tissue Eng. Part A. Mary Ann Liebert, Inc. 140 Huguenot Street, 3rd Floor New Rochelle, NY 10801 USA; 2010;16:233-243.

33. Nojima J, Kanomata K, Takada Y, Fukuda T, Kokabu S, Ohte S, et al. Dual roles of smad proteins in the conversion from myoblasts to osteoblastic cells by bone morphogenetic proteins. J Biol Chem [Internet]. ASBMB; 2010; 285:15577-15586. Available from: http://www.pubmedcentral.nih.gov/ articlerender.fcgi?artid $=2865305 \&$ tool $=$ pmcentrez\&rendertype $=$ abstract.

34. fang ZJ, Li G, yan CC, ling MC, mi LMC, chao CY, et al. Flavonoids of Herba Epimedii regulate osteogenesis of human mesenchymal stem cells through BMP and Wnt/ $\beta$-catenin signaling pathway. Mol Cell Endocrinol Elsevier. 2010;314:70-4.

35. Zhao J, Ohba S, Shinkai M, il CU, Nagamune T. Icariin induces osteogenic differentiation in vitro in a BMP- and Runx2-dependent manner. Biochem Biophys Res Commun Elsevier. 2008;369:444-8.

\section{Ready to submit your research? Choose BMC and benefit from:}

- fast, convenient online submission

- thorough peer review by experienced researchers in your field

- rapid publication on acceptance

- support for research data, including large and complex data types

- gold Open Access which fosters wider collaboration and increased citations

- maximum visibility for your research: over $100 \mathrm{M}$ website views per year

At BMC, research is always in progress.

Learn more biomedcentral.com/submissions 